\title{
Paerregaard, K. (2013). Peruanos en el mundo. Una etnografía global de la migración. Lima: Fondo Editorial de la Pontificia Universidad Católica del Perú.
}

\author{
Tomás P. Caycho ${ }^{1, a, c, *}$ \& Sergio A. Dominguez ${ }^{1, b, c}$ \\ ${ }^{1}$ Universidad Inca Garcilaso de la Vega, Lima, Perú.
}

\begin{abstract}
${ }^{a}$ Licenciado en Psicología y estudios de maestría en Psicología Educativa por la Universidad Nacional Mayor de San Marcos. Editor de la Revista Peruana de Psicología y Trabajo Social, ${ }^{\mathrm{b}}$ Licenciado en Psicología y magíster en Psicología Clínica por la Universidad Nacional Mayor de San Marcos, ${ }^{c}$ Docente del área de investigación de la Facultad de Psicología y Trabajo Social de la Universidad Inca Garcilaso de la Vega.
\end{abstract}

Recibido: $30-11-13$

Aprobado: 06-01-14

*Correspondencia

Email: tcaycho@uigv.edu.pe

\section{Citar Como:}

Caycho, T., \& Dominguez, S., (2013). Paerregaard, K. (2013). Peruanos en el mundo. Una etnografía global de la migración. Lima: Fondo Editorial de la Pontificia Universidad Católica del Perú.. Propósitos y Representaciones, 1(2), 215-219. doi: http://dx.doi.org/10.20511/pyr2013.vln2.49 
Karsten Paerregaard es doctor en Antropología por la Universidad de Copenhague, y actualmente se desempeña como profesor de Antropología del Departamento de Antropología Social en la Universidad de Gotemburgo, en Suecia. Su relación con el Perú es de larga data, siendo considerado uno de los mayores expertos en los procesos migratorios internos y externos del país, así como en el impacto sociocultural del cambio climático en la zona andina peruana. Por sus aportes, la Universidad del Centro del Perú le confirió el título de Doctor Honoris Causa en el año 2004. La obra que reseñamos ahora, Peruanos en el mundo. Una etnografía global de la migración, es una clara muestra de su interés académico y viene a complementar otro estudio publicado como Linking Separate Worlds: Urban Migrants and Rural Lives in Peru (1997). El libro tiene como objetivo "examinar la diversidad de relaciones y prácticas que constituyen las redes y organizaciones de los emigrantes y entender cómo es que estas se encuentran incrustadas en las estructuras económicas y políticas nacionales y globales” (p. 50).

¿Por qué analizar el proceso de migración peruana y no el de otros grupos de migrantes internacionales comparativamente mayores en cantidad, como los mexicanos o los indios, por citar dos ejemplos? Paerregaard señala diversas razones. En primer lugar, que con el paso de los años se observa un incremento del número de peruanos en el extranjero, llegando a representar hoy aproximadamente el $10 \%$ de la población nacional. En segundo lugar, que en ese proceso migratorio están representados peruanos de diversas clases sociales, sexos, grupos etarios y profesiones. En tercer lugar, que las migraciones peruanas en el extranjero no se centran en uno o dos lugares, como sucede, por ejemplo, con los cubanos en Miami o con los puertorriqueños en Nueva York, sino que, más bien, tienden a dispersarse por diferentes espacios.

Es así que el estudio del proceso migratorio peruano permite analizar y conceptualizar la migración a partir de una metodología analítica que pueda ser aplicable a procesos migratorios similares. Paerregaard analiza la migración como un proceso de inclusión y exclusión configurado por dos modos de diferenciación: interna y externa, los cuales traen a la luz la propia experiencia y perspectiva de los migrantes (diferenciación interna) y las relaciones de poder político que contextualiza el proceso migratorio (diferenciación externa). 
El libro está organizado en nueve capítulos. El primero brinda un análisis general del proceso de migración peruana, mientras que el segundo presenta una revisión histórica de los procesos migratorios peruanos en el siglo XX analizando, a su vez, los contextos económicos y políticos en los que se llevaron a cabo. El tercer capítulo describe las políticas migratorias de los países del Primer Mundo y cómo estas afectan el proceso de migración. En el cuarto capítulo, Paerregaard analiza los diferentes tipos de redes de los migrantes peruanos en el exterior y cómo estas pueden ir modificando su curso de desarrollo de acuerdo con variaciones en las políticas y los mercados de los países receptores.

Las instituciones y los acontecimientos que estimulan los procesos migratorios son descritos y analizados en el quinto capítulo, mientras que el capítulo seis presenta un análisis de las instituciones y organizaciones creadas por los migrantes peruanos en las ciudades donde se establecen, enfatizando en los conflictos internos que surgen al interior de aquellas. La intolerancia y los mecanismos de control de los países receptores de los migrantes, así como la formación de la idea de pertenencia y las variaciones en la noción de desigualdad social, son objeto del sétimo capítulo. Qué es la ilegalidad y cómo afecta la vida de los migrantes peruanos en el exterior son los temas que se tratan en el octavo capítulo.

Finalmente, en el capítulo nueve se presenta el resumen teórico y analítico de la investigación. Paerregaard concluye que "la implicancia analítica del estudio es que los peruanos de casi todas las clases sociales y grupos étnicos consideran que la movilidad geográfica es un medio importante a través del cual se puede alcanzar la movilidad social y, por ende, están dispuestos a adaptarse a las sociedades receptoras antes que conservar los lazos existentes con su país de origen" (p. 267).

¿Qué valor tiene este libro para el estudio psicológico del proceso migratorio? Partamos de considerar la migración como un fenómeno psicosociocultural que genera cambios importantes en diferentes aspectos de la vida de las personas, en la inserción a la comunidad y la estabilidad, en lo individual, familiar y económico (Ojeda, Cuenca \& Espinosa, 2008), exigiendo por esto un nivel de adaptación social (Bhugra, 2004). Con el fin de alcanzar dicho ajuste, el migrante requiere adaptarse desde el punto de vista emocional/afectivo y sociocultural/conductual. 
El primer tipo de adaptación se expresa en el nivel de bienestar subjetivo y la satisfacción por el nuevo estilo de vida que adopta. El segundo tipo se observa a través del aprendizaje de habilidades y conocimientos culturalmente apropiados en el lugar de destino. Así, los esquemas mentales y sociales del lugar de destino, las condiciones propias de su migración y los procesos psicológicos que involucran a la persona oriunda en su aceptación de la diferencia hacen que la inmigración se convierta en un fenómeno particularmente difícil y problemático (Patiño \& Kirchner, 2008).

El libro nos muestra, a través de su análisis cualitativo, una serie de estresores psicosociales que están en relación con la salud mental. La investigación psicológica muestra suficiente evidencia de que los principales problemas de salud que presentan los inmigrantes se relacionan con las condiciones socioeconómicas en las que viven, el nivel de estudios, el estado civil, el número de miembros del hogar y la presencia o ausencia de fuentes de apoyo social, entre otros.

Por lo mencionado anteriormente, a los inmigrantes se les ha considerado como un grupo de alto riesgo en el desarrollo de alteraciones psicológicas con repercusiones a nivel de la salud mental. Para que se logre una adecuada adaptación psicológica, es importante el tipo de personalidad del individuo, el manejo y ajuste que ha hecho de los cambios por los que ha atravesado en su historia y el apoyo o redes sociales con los que cuente. El contenido del libro es de suma importancia tomando en cuenta que muchos estudios de opinión pública muestran temor e incomprensión hacia la migración, haciendo que este proceso tenga relevancia política para los países americanos y europeos.

El texto ha sido escrito con el estilo característico del autor: claro, preciso y con un lenguaje que no cae en la jerga ni en los neologismos. La obra constituye un real y novedoso aporte al tema de la migración desde una perspectiva antropológica y psicológica, y no hace más que ratificar la figura de Paerregaard como uno de los más importantes científicos sociales dedicados a la investigación de los procesos migratorios. El lector hallará información importante para entender a los migrantes peruanos que radican en diversas ciudades del mundo, así como las influencias sociales, culturales y políticas que se ponen de manifiesto en este proceso. El enfoque interdisciplinario que se manifiesta en Peruanos en el mundo... permite una revisión más allá de la especialización, en busca de su llegada a un público amplio. 


\section{Referencias}

Bhugra, D. (2004). Migration and mental health. Acta Psychiatrica Scandinavica, 109, 243-258.

Ojeda, A.; Cuenca, J. \& Espinosa, D. (2008). Comunicación y afrontamiento como estrategias individuales que buscan facilitar la adaptación social en población migrante. Migración y Desarrollo, 11, 79-95.

Paerregaard, K. (1997). Linking Separate Worlds: Urban Migrants and Rural Lives in Peru. Oxford: Berg Publishers.

Patiño, C., \& Kirchner, T. (2008). Estrés y coping en inmigrantes latinoamericanos residentes en Barcelona. Revista Iberoamericana de Psicología, 1, 29-38. 